\title{
Evidence of superatom electronic shells in ligand-stabilized aluminum clusters
}

\author{
P. Andre Clayborne, ${ }^{1, a)}$ Olga Lopez-Acevedo, ${ }^{1}$ Robert L. Whetten, ${ }^{1,2}$ Henrik Grönbeck, ${ }^{3}$ \\ and Hannu Häkkinen ${ }^{1,4}$ \\ ${ }^{1}$ Department of Chemistry, Nanoscience Center, University of Jyväskylä, FI-40014 Jyväskylä, Finland \\ ${ }^{2}$ School of Chemistry and Biochemistry, Georgia Institute of Technology, Atlanta, Georgia 30332, USA \\ ${ }^{3}$ Competence Centre for Catalysis and Department of Applied Physics, Chalmers University of Technology, \\ SE-41296 Göteborg, Sweden \\ ${ }^{4}$ Department of Physics, Nanoscience Center, University of Jyväskylä, FI-40014 Jyväskylä, Finland
}

(Received 6 July 2011; accepted 12 August 2011; published online 6 September 2011)

\begin{abstract}
Ligand-stabilized aluminum clusters are investigated by density functional theory calculations. Analysis of Kohn-Sham molecular orbitals and projected density of states uncovers an electronic shell structure that adheres to the superatom complex model for ligand-stabilized aluminum clusters. In this current study, we explain how the superatom complex electron-counting rule is influenced by the electron-withdrawing ligand and a dopant atom in the metallic core. The results may guide the prediction of new stable ligand-stabilized (superatom) complexes, regardless of core and electronwithdrawing ligand composition. (C) 2011 American Institute of Physics. [doi:10.1063/1.3632087]
\end{abstract}

\section{INTRODUCTION}

Instrumental in cluster physics and chemistry is a thorough understanding of the electronic structure. The electronic structure determines the properties of clusters in the gas phase as well as for nanostructured materials fabricated by cluster assembly. ${ }^{1-6}$ The jellium electronic shell model considers the valence electrons and subjects them to a uniform background potential. The shape of the potential, based on the geometry as well as the type of atoms within the cluster, will yield discrete energy levels as solutions to the Schrödinger equation. ${ }^{7}$ In particular, the spherical uniform background (jellium) results in electronic levels or shells in the order of increasing main quantum number and angular momenta as, $1 \mathrm{~S}^{2} 1 \mathrm{P}^{6} 1 \mathrm{D}^{10}$ $2 \mathrm{~S}^{2} 1 f^{14} 2 \mathrm{P}^{6} 1 \mathrm{G}^{18}$. Large gaps between the highest occupied and lowest unoccupied molecular orbitals (HOMO-LUMO) occur for clusters with closed electronic shells and yields an enhanced stability for metallic clusters with the total number of electrons $\left(n_{e}\right)$ corresponding to $2,8,18,20,34,40,58$, etc.

The jellium electronic shell model that initially was used to explain electronic properties of bare simple-metal clusters, ${ }^{9-15}$ has recently been used to rationalize the stability of a series of clusters containing metallic cores surrounded by organic ligands. ${ }^{16-26}$ Contrary to the case of simple bare clusters, the number of delocalized valence electrons become dependent on the number of stabilizing ligands. For a cluster complex with the molecular formula $\left[\mathrm{A}_{\mathrm{N}} \mathrm{L}_{\mathrm{X}}\right]^{z}$, an equation can be written as

$$
n_{e}=N_{A} v_{A}-X_{L} w_{L}-z,
$$

where the shell closing electron count $n_{e}$ of the metallic core satisfies a number from the jellium electron shell model; where $N_{A}$ is the number of atoms in the core, $v_{A}$ is the atomic

\footnotetext{
a) Author to whom correspondence should be addressed. Electronic mail: penee.a.clayborne@jyu.fi.
}

valence, $X_{L}$ is the number of ligands, $w_{L}$ is the number of electrons withdrawn by the ligand, and $z$ is the charge of the cluster. If the number of electrons in the cluster core corresponds to the $n_{e}$ in the jellium model, the cluster complex is considered a superatom complex.

The use of the superatom complex model has proven successful for a variety of cluster complexes with numerous compositions. The $\mathrm{Au}_{102}(\mathrm{p}-\mathrm{MBA})_{44}$ cluster has a sizeable HOMO-LUMO gap that opens at the 58-electron shell closing ${ }^{16,22}$ and the superatom complex $\mathrm{Au}_{25}(\mathrm{SR})_{18}{ }^{-}$ has eight electrons. ${ }^{23,24}$ Recently, we have demonstrated that $\mathrm{Al}_{50}\left(\mathrm{C}_{5} \mathrm{Me}_{5}\right)_{12}\left(\mathrm{Me}=\mathrm{CH}_{3}\right)$ can be understood within the model as a superatom with 138 electrons. ${ }^{25}$ Furthermore, other group 13 clusters, such as metalloids (e.g., $\left.\mathrm{Ga}_{23}\left[\mathrm{~N}\left(\mathrm{Si}\left(\mathrm{CH}_{3}\right)_{3}\right)_{2}\right]_{11}\right)$, have been predicted to adhere to the model. 26,27

Despite the success of the superatom complex model in the interpretation of various clusters, the model has come under scrutiny for smaller $\mathrm{Al}_{\mathrm{n}} \mathrm{L}_{\mathrm{m}}$ clusters. An integral piece of the controversy stems from the tendency of smaller bare aluminum clusters to lack pronounced $s p$-hybridization and may form directional bonding with organic ligands. Thus, chemists and physicist have interpreted the stability of small ligand-stabilized clusters with various models. For example, the $\mathrm{Al}_{4}\left(\mathrm{C}_{5} \mathrm{Me}_{5}\right)_{4}\left(\mathrm{Me}=\mathrm{CH}_{3}\right)$ cluster has been explained with backbonding of individual $\mathrm{AlCp}^{*}\left(\mathrm{Cp}^{*}=\mathrm{C}_{5} \mathrm{Me}_{5}\right)$ molecular units. $^{28}$ Kiran et al. showed that the jellium model was valid for a series of $\mathrm{Al}_{\mathrm{n}} \mathrm{H}_{\mathrm{m}} \cdot{ }^{29}$ In contrast, Jung et al. proposed $\mathrm{Al}_{\mathrm{n}} \mathrm{H}_{\mathrm{m}}$ clusters gain stability through molecular orbital overlap. ${ }^{30}$

The varying views on accounting for the stable behavior of $\mathrm{Al}_{\mathrm{n}} \mathrm{L}_{\mathrm{m}}$ clusters and the recent success in understanding the ligand-stabilized system $\mathrm{Al}_{50} \mathrm{Cp}^{*}{ }_{12}$ (1) have motivated us to explore a series of small ligand-stabilized aluminum clusters. In this report, we provide clear evidence of an electronic shell structure for $\mathrm{Al}_{4} \mathrm{Cp}_{4}(2), \mathrm{Al}_{8} \mathrm{Cp}_{4}(3)$, and $\mathrm{Al}_{4}\left[\mathrm{Si}(\mathrm{t}-\mathrm{Bu})_{3}\right]_{4}$ (4) 


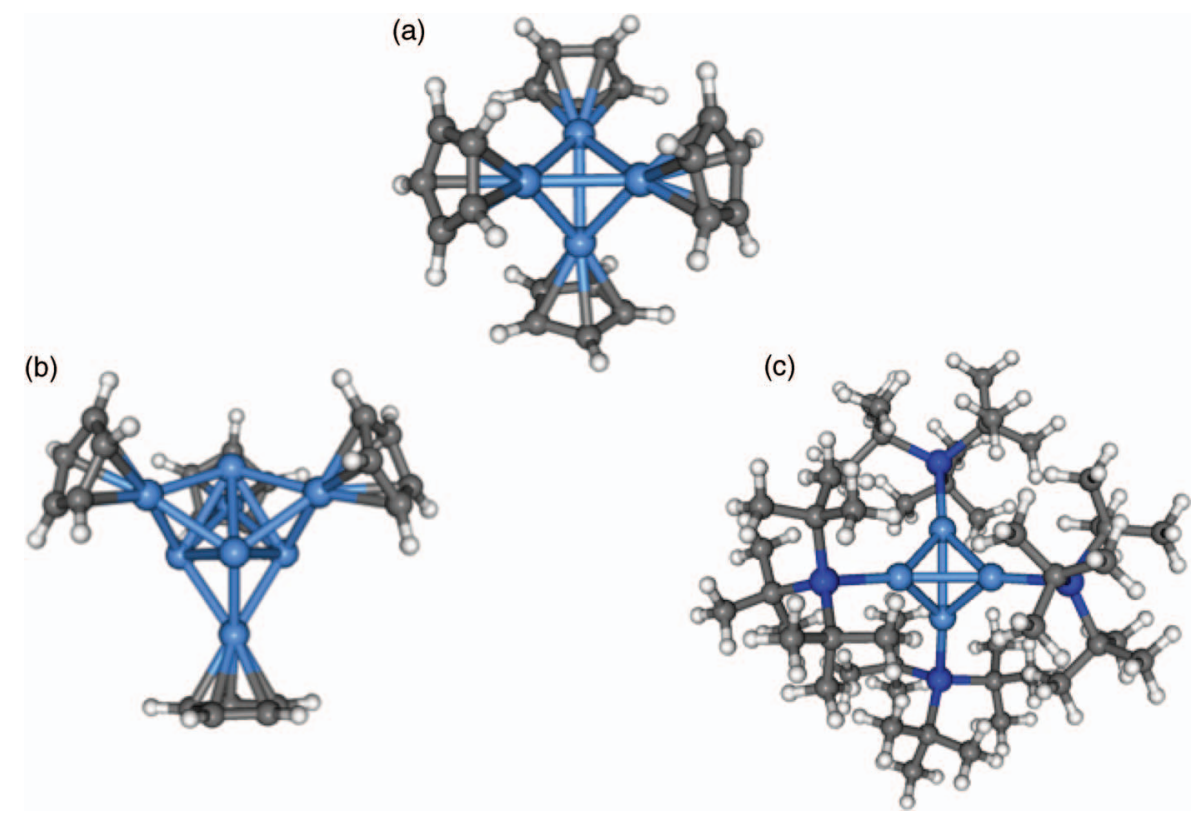

FIG. 1. Relaxed geometries of (a) $\mathrm{Al}_{4} \mathrm{Cp}_{4}$ (2), (b) $\mathrm{Al}_{8} \mathrm{Cp}_{4}$ (3), and (c) $\mathrm{Al}_{4}\left[\mathrm{Si}^{t} \mathrm{Bu}_{3}\right]_{4}$ (4). The light blue, gray, white, and dark blue balls represent the $\mathrm{Al}$, $\mathrm{C}$, $\mathrm{H}$, and $\mathrm{Si}$ atoms, respectively.

$\left.\left(\mathrm{Cp}=\mathrm{C}_{5} \mathrm{H}_{5} ; \mathrm{t}-\mathrm{Bu}=\mathrm{C}_{[} \mathrm{CH}_{3}\right]_{3}\right)$. By use of the superatom complex model, we find the clusters have electronic shell closings at 8,20 , and 8 delocalized electrons, respectively. The observed electronic shell yields an explanation for the optical properties observed in the solution of $\mathbf{2}$ and $\mathbf{4}$.

\section{COMPUTATIONAL METHOD}

We used the grid-based projector-augmented wave code (GPAW) with the generalized gradient approximation of Perdew, Burke, and Ernzerhof (PBE) to account for the exchange-correlation interaction. ${ }^{31,32} \mathrm{H}(1 s), \mathrm{C}(2 s 2 p)$, $\mathrm{Si}(3 s 3 p)$, and $\mathrm{Al}(3 s 3 p)$ electrons are treated in the valence, and the electron density is solved in a grid with $0.18 \AA$ spacing. Clusters 2-4 were fully optimized with no symmetry constraints based on previously reported structures. ${ }^{28,33}$ The relaxed structures are reported in Fig. 1. To analyze the superatomic electronic structure, the Kohn-Sham molecular orbitals were projected on center-of-mass spherical harmonics in a spherical volume, including the metal core, as described previously. ${ }^{25}$

\section{RESULTS AND DISCUSSION}

We begin this discussion by considering $\mathrm{Al}_{4} \mathrm{Cp}_{4}$ (2) (Fig. 1(a)). Cluster $\mathbf{2}$ has been previously explained as four distinct AlCp units that form a stable cluster entity due to backbonding of these units. ${ }^{28}$ However, the previous explanation is hard to envision as backbonding requires $d$-orbitals to be available along with the $p$-orbitals of the ligand to facilitate this type of chemical bonding. We first analyzed the Kohn-Sham orbital correlation diagram for the $\mathrm{Al}_{4} \mathrm{Cp}_{4}$ (2), with $\mathrm{Al}_{4}{ }^{4+}$ core and $\mathrm{Cp}^{-}$ligands (Fig. 2). ${ }^{34}$ (The use of the formal charge separation is supported by a Bader charge analysis, which reveals that each aluminum atom loses 0.79 lel to the $\mathrm{Cp}$ ligand with ionic character, similar to cluster $\mathbf{1}^{26,35}$ ) The analysis reveals a clear sequence of jellium-like states of the $\mathrm{Al}_{4}{ }^{4+}$, with a three-fold degenerate $1 \mathrm{P}$-symmetric HOMO state and 1S-symmetric HOMO-1 state. These states are only slightly perturbed in the ligand protected cluster and the $1 \mathrm{P}$ state does not hybridize with the ligand states. This is instead the case for $1 \mathrm{~S}$ that forms one bonding and one anti-bonding combination with the total symmetric $\pi$-orbital of $\mathrm{Cp}$.

This initial analysis agrees with the prediction from Eq. (1) that gives $n_{e}=8$ for cluster 2. Furthermore, the metal-core projected local density of states (PLDOS) reveals the superatomic shell filling of the $\mathrm{S}$ and $\mathrm{P}$ states as shown in Fig. 3(a). The LUMO is composed of the $2 \mathrm{~S}$ and $1 \mathrm{D}$ states (the 1D states are split into two subgroups by the $T_{d}$

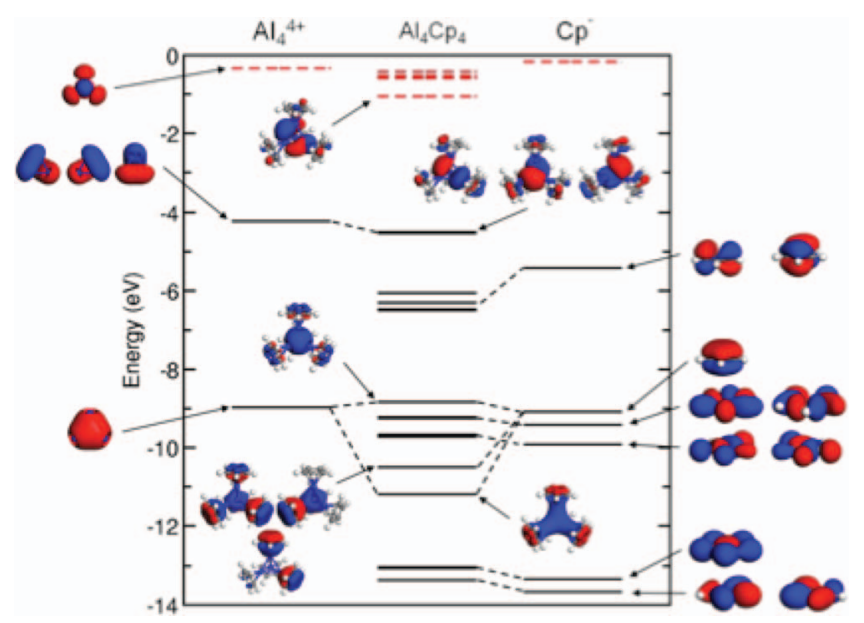

FIG. 2. Valence Kohn-Sham orbital correlation diagram for $\mathrm{Al}_{4} \mathrm{Cp}_{4}$. The solid (dashed) lines indicate occupied (unoccupied) states. The eigenvalues for $\mathrm{Al}_{4}{ }^{4+}$ and $\mathrm{Cp}^{-}$have been aligned to the spectrum of $\mathrm{Al}_{4} \mathrm{Cp}_{4}$ via the $\mathrm{Al}(1 s)$ and $\mathrm{C}(1 s)$ states, respectively. A selected set of molecular orbitals is shown. 
symmetry). The HOMO-LUMO gap is $3.38 \mathrm{eV}$ (Table I), which is a sign of the electronic stability that corresponds to the expected shell closing.

In cluster $\mathbf{3}$ ( $T_{d}$ symmetry), there is a tetrahedral $\mathrm{Al}_{4}$ core surrounded by a shell of four aluminum atoms and an outer ligand shell of four Cp units (Fig. 1(b)). It should be noted that although this cluster is abundant in mass spectrometry, the crystal structure has not yet been solved, and we consider the structure proposed by Huber et al..$^{33}$ Based on Eq. (1), we find $n_{e}=20$ for 3 , and the expected shell-filling pattern, $1 \mathrm{~S}^{2}$ $1 \mathrm{P}^{6} 1 \mathrm{D}^{10} 2 \mathrm{~S}^{2}$ (Table I), is clearly confirmed from the PLDOS analysis (Fig. 3(b)). It is interesting to note that the 1D states are split similar to the LUMO states for cluster $\mathbf{2}$ due to the $T_{d}$ symmetry. Following the expected shell-filling sequence, the LUMO has $1 \mathrm{~F}$ and $2 \mathrm{P}$ composition. It has previously been suggested ${ }^{26}$ that the ligand should be considered to be the organo-metallic AlCp; however, this is a topic of debate and previously it was shown that cluster $\mathbf{1}$ should be viewed as an $\mathrm{Al}_{50}$ core with $12 \mathrm{Cp}^{*}$ ligands based on a projection of spherical harmonics with varying radius. ${ }^{26}$ Thus, we performed a similar analysis on $\mathbf{3}$ which illustrates the importance of including the outer aluminum atoms that contribute to form the higher occupied delocalized states. The electronic stability is further confirmed through the calculated HOMO-LUMO gap of $2.12 \mathrm{eV}$.

Cluster 4 presents an interesting composition with an $\mathrm{Al}_{4}$ core surrounded by four organo-metallic $\mathrm{Si}(\mathrm{t}-\mathrm{Bu})_{3}$ ligands. ${ }^{28}$ The structural results of our calculations vary only by 0.03 angstroms from the experimental structure (Table S1). ${ }^{42}$ In this cluster, the silicon atom should be viewed as part of the ligand. If silicon instead is considered as a part of the cluster
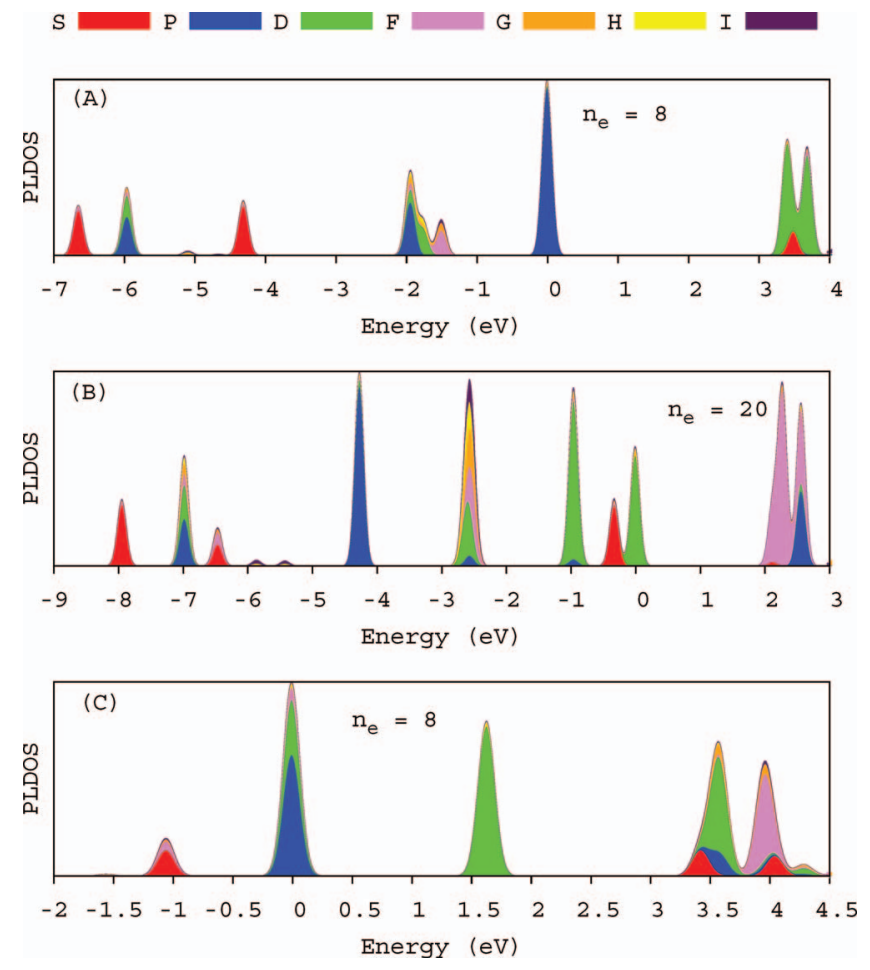

FIG. 3. Metal-core projected local density of states for the $\mathrm{Al}_{4} \mathrm{Cp}_{4}$ (a), $\mathrm{Al}_{8} \mathrm{Cp}_{4}$ (b), and $\mathrm{Al}_{4}\left[\mathrm{Si}(\mathrm{t}-\mathrm{Bu})_{3}\right]_{4}$ (c) clusters. The number in bold face denotes the number of electrons in the system. The HOMO energy is at zero.
TABLE I. Number of valence electrons $\left(n_{e}\right)$, electronic configuration, adiabatic ionization potentials, adiabatic electron affinities, and theoretical determined HOMO-LUMO gap (Gap) for the clusters in this study. The ionization potentials, electron affinities, and HOMO-LUMO gaps are given in $\mathrm{eV}$.

\begin{tabular}{lrccrc}
\hline \hline & $n_{e}$ & Configuration & Gap & EA & IP \\
\hline $\mathrm{Al}_{4} \mathrm{Cp}_{4}$ & 8 & $1 \mathrm{~S}^{2} 1 \mathrm{P}^{6}$ & 3.38 & 0.14 & 5.71 \\
$\mathrm{Al}_{8} \mathrm{Cp}_{4}$ & 20 & {$\left[\mathrm{Al}_{4} \mathrm{Cp}_{4}\right] 1 \mathrm{D}^{10} 2 \mathrm{~S}^{2}$} & 2.12 & 0.50 & 5.36 \\
$\mathrm{SiAl}_{14} \mathrm{Cp}_{6}$ & 40 & {$\left[\mathrm{Al}_{8} \mathrm{Cp}_{4}\right] 1 \mathrm{~F}^{14} 2 \mathrm{P}^{6}$} & 1.90 & 1.14 & 5.29 \\
$\mathrm{Al}_{4}\left(\mathrm{Si}{ }^{\mathrm{t}} \mathrm{Bu}\right)_{4}$ & 8 & $1 \mathrm{~S}^{2} 1 \mathrm{P}^{6}$ & 1.62 & 1.60 & 5.80 \\
\hline \hline
\end{tabular}

core, Eq. (1) would be augmented with an additional term to account for the valence electrons of the silicon atom via

$$
n_{e}=N_{A} v_{A}+M_{B} v_{B}-X_{L} w_{L}-z
$$

where the chemical formula would be $\left[\mathrm{A}_{\mathrm{N}} \mathrm{B}_{\mathrm{M}} \mathrm{L}_{\mathrm{X}}\right]^{z}$ (with $M_{B}$ and $v_{B}$ the number and atomic valence of the additional atom $\mathrm{B}$, respectively). In the case where Eq. (2) was used, the 1S and $1 \mathrm{P}$ would be filled; however, the remaining eight electrons could result in two different electronic configurations in the 1D shell. The first would result in an open shell configuration, via two unpaired electrons in the 1D state (high spin). The second, would yield a closed electronic shell via electronic shell splitting, which has been shown to occur in bare aluminum clusters. ${ }^{36}$ In this case, the 1D states are expected to split with the HOMO having four D states and the LUMO having the remaining D states.

The PLDOS and molecular orbital analyses show a superatomic shell filling with 1P states as predicted from Eq. (1) for the HOMO (Fig. 2(c)). Similarly, the LUMO and LUMO +1 are composed of $\mathrm{D}$ states, followed by a gap with the $\mathrm{LUMO}+2$, $\mathrm{LUMO}+3$, and LUMO +4 being the $2 \mathrm{~S}$ and remaining D states, respectively (Fig. 3(c)). We performed the same type of analysis as for cluster $\mathbf{3}$, varying the radius to see if the silicon atoms should be considered as part of the cluster core. By comparison, there is only an arbitrary change in the occupied and unoccupied states of $\mathbf{4}$ when including the silicon atoms (Fig. S2). ${ }^{26,42}$ Consequently, it is clear that the silicon atoms should be considered as part of the ligands and not as the cluster core based on the analysis. That $\mathbf{4}$ could be viewed as a $1 \mathrm{~S}^{2} \mathrm{P}^{6}$ superatom is consistent with an analysis of the valence electronic structure and the corresponding Kohn-Sham orbitals (Fig. 4). ${ }^{34}$ The HOMO level is three-fold degenerated where the three states have the characteristic Plobes. The HOMO-1 state has clear S-character.

As Eq. (2) does not appear to be valid for cluster 4, it is interesting to show an example where Eq. (2) actually is valid. To do this, we investigated $\mathrm{SiAl}_{14} \mathrm{Cp}_{6}(\mathbf{5}){ }^{37}$ The resolved atomic structure of $\mathbf{5}$ (Fig. S3) ${ }^{42}$ displays a central $\mathrm{Si}$ atom surrounded by a shell of $14 \mathrm{Al}$ atoms with a final shell of six Cp units. Using Eq. (2) we find $n_{e}=40$, yielding the 1F2P electronic shells completely filled which is confirmed in the PLDOS (Fig. S3). ${ }^{38,42}$ Though we have presented only one aluminum metalloid, Eq. (2) should hold for other ligandstabilized systems (as well as superatom complexes) with different types of ligands, charge, and/or composition as long as there is electron delocalization within the cluster core. For example, $\mathrm{SiAl}_{14}\left[\mathrm{~N}(\mathrm{Dipp}) \mathrm{SiMe}_{3}\right]_{6}$ and $\mathrm{SiAl}_{11} \mathrm{Cp}_{2}{ }_{2}{ }^{+}$represent 


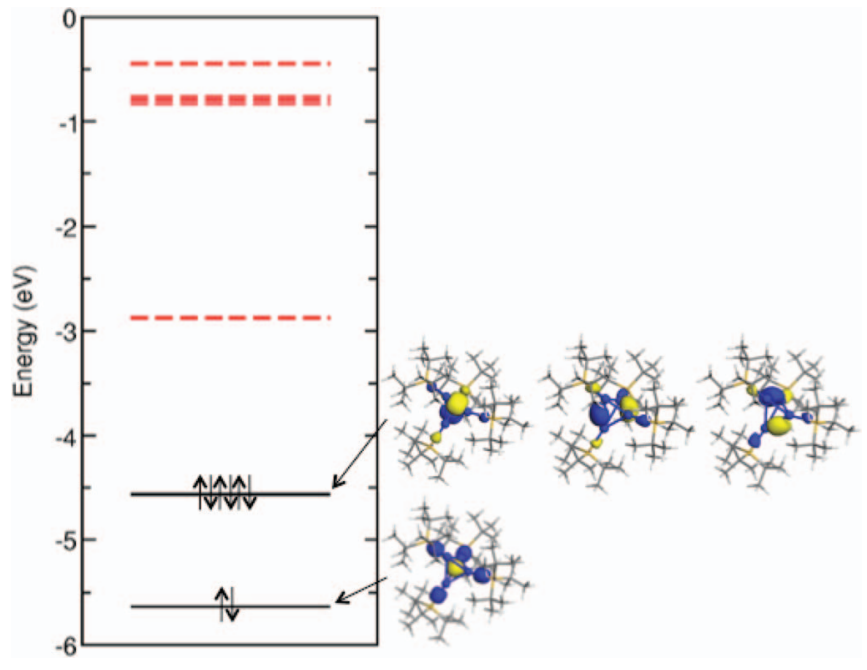

FIG. 4. Valence Kohn-Sham orbital correlation diagram for $\mathrm{Al}_{4}\left(\mathrm{Si}^{\mathrm{t}} \mathrm{Bu}_{3}\right)_{4}$. The solid (dashed) lines indicate occupied (unoccupied) states. A selected set of molecular orbitals are shown.

superatom complexes with shell closings of 40 and 34 electrons, respectively. ${ }^{37,39}$ Further the halogenated compound $\mathrm{Si}_{2} \mathrm{Al}_{13} \mathrm{Cp}_{6}{ }_{6} \mathrm{Cl}$ would also have 40 delocalized electrons (the $\mathrm{Cl}$ atom would withdraw one electron similar to the $\mathrm{Cp}^{*}$ ligand), thus could be considered a halogenated superatom complex similar to the halogenated gold complexes previously reported. ${ }^{16,37}$

The HOMO-LUMO gap, ionization potential (IP), and electron affinity (EA) values display both a size-dependent and ligand-dependent variation. The smallest cluster $\mathbf{2}$ has the largest IP, the smallest EA, and the largest HOMO-LUMO gap. However, with increasing cluster size, the HOMOLUMO gap and IP become smaller, while the EA becomes larger. The IP trend is similar to what is found on the periodic table of elements. The binding energy of the ligands $(\mathrm{Cp})$ to the cluster core tends to remain large at $4.1 \mathrm{eV}$ for the removal of a $\mathrm{Cp}^{-}$for $\mathbf{2}$ and $4.2 \mathrm{eV}$ for $\mathbf{1}$, as reported previously. ${ }^{25}$ The high binding energy shows that $\mathrm{Cp}$ and $\mathrm{Cp}\left({ }^{*}\right)$ act as protective substituents to the aluminum cluster core. This points to the protective nature of the $\mathrm{Cp}$ or $\mathrm{Cp}\left(^{*}\right)$ as a protective substituent to an aluminum cluster core. For ligand-protected gold clusters, the trends in the theoretical HOMO-LUMO gaps correlate with trends for measured electrochemical and optical gaps. The HOMO-LUMO gap $3.38 \mathrm{eV}$ for 2 predicts absorption in the UV region, which agrees with the observed colorless solution of 2. ${ }^{37}$ Figure 5(a) shows a calculated optical spectra for 2 , which shows a strong absorption peak at $3.5 \mathrm{eV}$ clearly in the UV region. Figure 5(b) gives the calculated optical absorption spectra for 4 . There are three peaks in the spectrum at 1.7, 2.1, and $3.2 \mathrm{eV}$, which is in agreement with the observed violet color in solution for the cluster compound. Furthermore, it is interesting to note that these small superatom complexes show trivalent aluminum behavior. Gas phase $\mathrm{Al}_{\mathrm{N}}$ clusters are known to show monovalent behavior, (i.e., lack of $s-p$ hybridization) and open geometries up to $\mathrm{N}$ $=5$. Thus, the ligands drive the compact three-dimensional packing of the Al core facilitating the $s-p$ hybridization for this small size. ${ }^{40}$
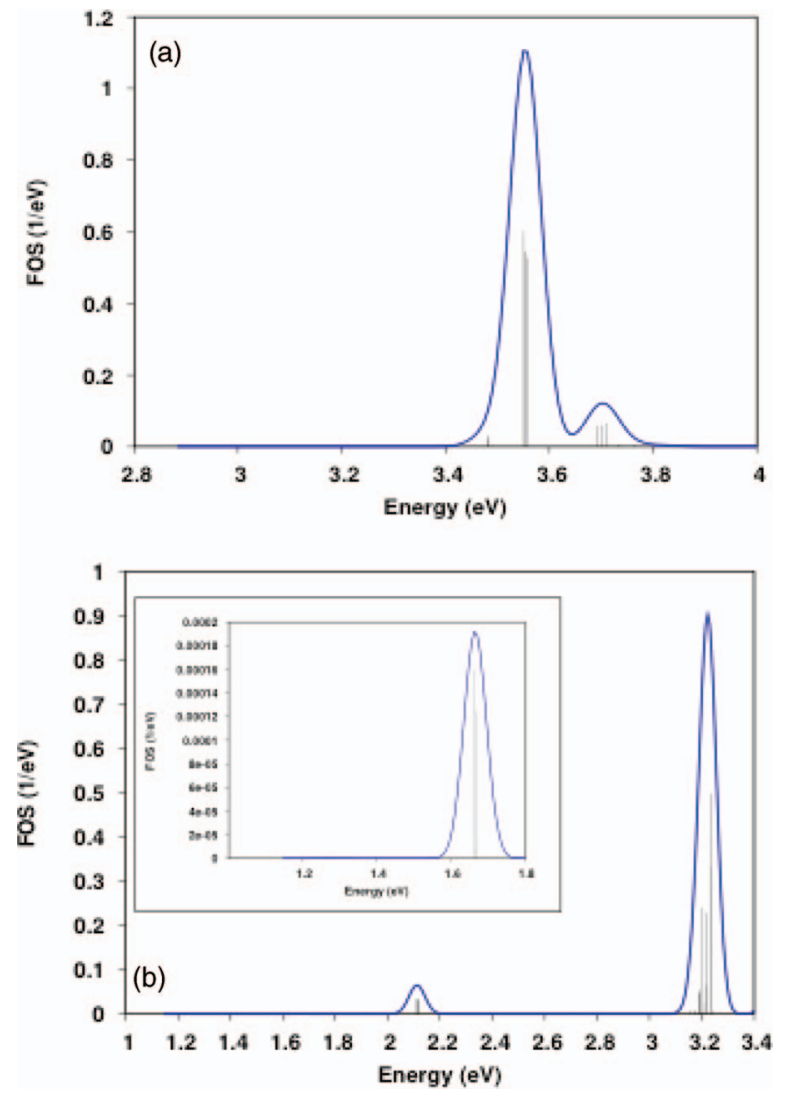

FIG. 5. Theoretical photoabsorption spectrum (folded oscillator strengths) of 2 (a) and 4 (b). The sticks denote the oscillator strengths of individual optical lines. The inset of (b) is a magnified view of the spectra from 1.2 to $1.8 \mathrm{eV}$.

\section{CONCLUSIONS}

By use of a combination of molecular orbital and projected density of states analyses, we have shown evidence of superatom electronic shell in ligand-stabilized aluminum clusters similar to $\mathrm{Al}_{50} \mathrm{Cp}^{*}{ }_{12}$. The equations presented here provide a simple tool for predictions of electronically closedshell ligand-stablized clusters, regardless of core or ligand (withdrawing) composition. Since it has been shown previously that both the geometry and electronic structure can influence the reactivity of a cluster, we hope these results promote further work on the effects of the ligand as it pertains to the geometry and electronic shell for reactivity in other ligand-stabilized clusters. ${ }^{41}$

\section{ACKNOWLEDGMENTS}

This work was supported by the Academy of Finland through projects 128341, 139614, and the Finland Distinguished Professor Program. The computational resources were provided by the CSC - the Finnish IT Center for Science in Espoo.

${ }^{1}$ S. A. Claridge, A. W. Castleman, S. N. Khanna, C. B. Murray, A. Sen, and P. S. Weiss, ACS Nano 3, 244 (2009).

${ }^{2}$ P. Jena, J. Phys. Chem. Lett. 2, 206 (2011).

${ }^{3}$ P. Jena and A. W. Castelman, Proc. Natl. Acad. Sci. U.S.A. 103, 10560 (2006). 
${ }^{4}$ S. N. Khanna and P. Jena, Phys. Rev. Lett. 69, 1664 (1992).

${ }^{5}$ S. N. Khanna and P. Jena, Phys. Rev. B 51, 13705 (1995).

${ }^{6}$ A. W. Castleman and S. N. Khanna, J. Phys. Chem. C 113, 2664 (2009).

${ }^{7}$ W. A. de Heer, Rev. Mod. Phys. 65, 611 (1993).

${ }^{8}$ W. D. Knight, K. Clemenger, W. A. de Heer, W. A. Saunders, M. Y. Chou, and M. L. Cohen, Phys. Rev. Lett. 54, 2141 (1984).

${ }^{9}$ T. Inoshita, S. Ohnishi, and A. Oshiyama, Phys. Rev. Lett. 57, 2560 (1986).

${ }^{10}$ L. Ma, B. Issendorff, and A. Aguado, J. Chem. Phys. 132, 104303 (2010).

${ }^{11}$ X. Li, H. Wu, X. B. Wang, and L. S. Wang, Phys. Rev. Lett. 81, 1909 (1998).

${ }^{12}$ K. E. Schriver, J. L. Persson, E. C. Honea, and R. L. Whetten, Phys. Rev. Lett. 64, 2539 (1990).

${ }^{13}$ D. E. Bergeron, A. W. Castleman, Jr., T. Morisato, and S. N. Khanna, Science 304, 84 (2004).

${ }^{14}$ D. E. Bergeron, P. J. Roach, A. W. Castleman, N. O. Jones, and S. N. Khanna, Science 307, 231 (2005).

${ }^{15}$ A. Grubisic, X. Li, S. T. Stokes, K. Vetter, G. G. Ganteför, K. H. Bowen, P. Jena, B. Kiran, R. Burgert, and H. Schnöckel, J. Chem. Phys. 131, 121103 (2009).

${ }^{16}$ M. Walter, J. Akola, O. Lopez-Acevedo, P. D. Jadzinsky, G. Calero, C. J. Ackerson, R. L. Whetten, H. Grönbeck, and H. Häkkinen, Proc. Natl. Acad. Sci. U.S.A. 105, 9157 (2008).

${ }^{17}$ O. Lopez-Acevedo, J. Rintala, S. Virtanen, C. Femoni, C. Tiozzo, H. Grönbeck, M. Pettersson, and H. Häkkinen, J. Am. Chem. Soc. 131, 12573 (2009).

${ }^{18}$ O. Lopez-Acevedo, J. Akola, R. L. Whetten, H. Grönbeck, and H. Häkkinen, J. Phys. Chem. C 113, 5035 (2009).

${ }^{19}$ J. Akola, K. A. Kacprzak, O. Lopez-Acevedo, M. Walter, H. Grönbeck, and H. Häkkinen, J. Phys. Chem. C 114, 15986 (2010).

${ }^{20}$ O. Lopez-Acevedo, H. Tsunoyama, T. Tsukuda, H. Häkkinen, and C. M. Aikens, J. Am. Chem. Soc. 132, 8210 (2010).

${ }^{21}$ C. M. Aikens, J. Phys. Chem. Lett. 2, 99 (2011).

${ }^{22}$ P. D. Jadzinsky, G. Calero, C. J. Ackerson, D. A. Bushnell, and R. D. Kornberg, Science 318, 5849 (2007).

${ }^{23}$ J. Akola, M. Walter, R. L. Whetten, H. Häkkinen, and H. Grönbeck, J. Am. Chem. Soc. 130, 3756 (2008).

${ }^{24}$ It should be noted that there are many stable complexes whose number of electrons can be counted by using the equation from the superatom complex model; however, the number of electrons do not adhere to the spherical jellium electron counts, such as $\mathrm{Au}_{38}(\mathrm{SR})_{34}$ (Ref. 20) and $\mathrm{Au}_{36}(\mathrm{SR})_{23}$ (P. R. Nimmala and A. Dass, J. Am. Chem. Soc. 133, 24 (2011)).

${ }^{25}$ P. A. Clayborne, O. Lopez-Acevedo, R. L. Whetten, H. Gronbeck, and H. Hakkinen, Eur. J. Inorg. Chem. 2011(17), 2649.

${ }^{26}$ O. Lopez-Acevedo, P. A. Clayborne, and H. Häkkinen, Phys. Rev. B 84, 035434 (2011).
${ }^{27}$ A. Schnepf, G. Stosser, and H. Schnöckel, Angew. Chem. 114, 1959 (2002).

${ }^{28}$ C. Dohmeier, C. Robl, M. Tacke, and H. Schnockel, Angew. Chem., Int. Ed. 30, 564 (1991); A. Purath, C. Dohmeier, A. Ecker, and H. Schnöckel, Organometallics 17, 1894 (1998).

${ }^{29}$ B. Kiran, P. Jena, X. Li, A. Grubisic, S. T. Stokes, G. F. Ganteför, K. H. Bowen, R. Burgert, and H. Schnöckel, Phys. Rev. Lett. 98, 256802 (2007); ibid 100, 199702 (2008).

${ }^{30}$ J. Jung, H. Kim, and Y.-K. Han, J. Am. Chem. Soc. 133, 6090 (2011); J. Jung, H. Kim, and Y.-K. Han, Phys. Rev. Lett. 100, 199701 (2008).

${ }^{31}$ J. J. Mortensen, L. Hansen, and K. W. Jacobsen, Phys. Rev. B 71, 035109 (2005); J. Enkovaara, C. Rostgaard, J. J. Mortensen, J. Chen, M. Dulak, L. Ferrighi, J. Gavnholt, C. Glinsvad, V. Haikola, H. Hansen, H. Kristoffersen, M. Kuisma, A. Larsen, L. Lehtovaara, M. Ljungberg, O. Lopez- Acevedo, P. Moses, J. Ojanen, T. Olsen, V. Petzold, N. Romero, J. Stausholm-Moller, M. Strange, G. Tritsaris, M. Vanin, M. Walter, B. Hammer, H. Häkkinen, G. Madsen, R. Nieminen, J. Norskov, M. Puska, T. Rantala, J. Schiotz, K. Thygesen, and K. W. Jacobsen, J. Phys.: Condens. Matter 22, 253202 (2010); M. Walter, H. Häkkinen, L. Lehtovaara, M. Puska, J. Enkovaara, C. Rostgaard, and J. J. Mortensen, J. Chem. Phys. 128, 244101 (2008). The gpaw code is freely available at https://wiki.fysik.dtu.

${ }^{32}$ J. P. Perdew, K. Burke, and M. Ernzerhof, Phys. Rev. Lett. 77, 3865 (1996).

${ }^{33}$ M. Huber, P. Henke, and H. Schnöckel, Chem.-Eur. J. 15, 12180 (2009).

${ }^{34}$ This analysis was performed with the dmol program. See B. Delley, J. Chem. Phys. 113, 7756 (2000).

${ }^{35}$ R. F. W. Bader, Atoms in Molecules (Clarendon, Oxford, 1990); W. Tang, E. Sanville, and G. Henkelman, J. Phys.: Condens. Matter 21, 7 (2009).

${ }^{36}$ P. J. Roach, W. H. Woodward, A. C. Reber, S. N. Khanna, and A. W. Castleman, Phys Rev. B 81, 19504 (2010).

${ }^{37}$ A. Purath, C. Dohmeier, A. Ecker, R. Köppe, H. Krautscheid, H. Schnöckel, R. Ahlrichs, C. Stoermer, J. Friedrich, and P. Jutzi, J. Am. Chem. Soc. 122, 6955 (2000); M. Huber, J. Hartig, K. Koch, and H. Schnöckel, Z. Anorg. Allg. Chem. 635, 3 (2009).

${ }^{38}$ The prediction of $\mathrm{SiAl}_{14} \mathrm{Cp}_{6}$ having 40 electrons was also predicted previously. See Ref. 37b.

${ }^{39}$ K. Wieb and H. Schnöckel, Anal. Bioanal. Chem. 377, 7 (2003).

${ }^{40}$ B. K. Rao and P. Jena, J. Chem. Phys. 111, 1890 (1999).

${ }^{41}$ P. J. Roach, W. H. Woodward, A. W. Castleman, A. C. Reber, and S. N. Khanna, Science 323, 5913 (2009).

${ }^{42}$ See supplementary material at http://dx.doi.org/10.1063/1.3632087 for comparison of the relaxed structure to the experimental structure 4, angular momentum percentage as a function of radius for $\mathbf{3}$ and $\mathbf{4}$, PLDOS, and structure for $\mathbf{5}$. 